\section{EXTENSIVE ARSENICAL POISONING.}

\section{By Alex. Thom, M.A., M.D. \& C.M. ED., D.P.H. R.C.S.E.}

INDIVIDUAL, cases of poisoning by arsenic are not very uncommon, and have lately attracted considerable attention, but such poisoning is fortunately somewhat rarely met with on an extensive scale, and I think I am warranted in placing on record an occurrence of that nature where the symptoms were very characteristic and the materies morbi was clearly traced to some sugar.

On Saturday, Sunday, and Monday, the 4th, 5th, and 6th of April, the inhabitants of the lower part of Crieff, known as the Bridgend, were thrown into a state of consternation by what seemed to them the outbreak of an epidemic of vomiting with severe pain. The greater number of the cases, of which there were over a hundred, occurred within a limited area which might be embraced by a radius of an eighth or a sixth of a mile, and, speaking generally, were in families of the artisan class. The chief symptoms were pain and heat in the stomach, nausea, retching, and vomiting (the vomited matter being frequently brown and bilious-looking, and in some cases streaked with blood), great thirst and extreme depression, injection of the conjunctivre, and sometimes swelling of the face and eyelids. My assistant, Dr. Andrew Young, who attended the great majority of the cases (he saw over eighty in the course of four days), reports that in some cases severe purging and tenesmus were marked symptoms at the outset of the attack, but were not present as a rule, and that stran. gury was complained of only by a few. Several complained of cramp in various muscles. The symptoms appeared in from ten minutes to three hours after ingestion of a meal, which in almost every instance included tea. As a rule the more acute symptoms passed off in from thirtysix to forty-eight hours, though in some instances they lasted four or five days, but left the patient weak and depressed. Many suffered for days from severe headache and nondescript abdominal pains of a colicky nature. Where the symptoms lasted longer there was well-marked -edema of the eyelids and swelling of the face, with white rfurred tongue, great thirst, also sharp pains in the intestines and diarrhœea, with shreddy mucous discharge tinged with blood. Many complained of feeling the cold acutely, and a few suffered from severe coryza. I regrec to say that there have been two fatal cases-a wood carter aged seventy-two, and his wife aged about fifty-four. Both these suffered severely from purging and tenesmus, with great heat in the intestines, and excoriations round the anus, scrotum, and labia, and in their case retching and vomiting continued until death, which occurred on the eight and ninth days respectively.

Poisoning by arsenic at once suggested itself as best nexplaining the symptoms. Indeed, in many of the patients these were so typical that there was almost no room left for doubt, and the treatment adopted was in accordance with that opinion. It was not difficult either to arive at a conclusion as to the probable vehicle. The water and milk supplies were at once eliminated, and also all the ordinary articles of diet except tea and sugar. Some of the sufferers had noticed that the tea had a dark appearance and a peculiar taste, but the majority had been using the same tea for a considerable time, having had a large stock. All the families attacked had got a fresh supply of sugar, however, on the Friday or Saturday, and from one particular merchant. In one family some members took no sugar with their tea, and these escaped, while the others who did take sugar all suffered. In another family, one member had taken no tea and escaped for a time, but suffered like the rest after having partaken of the sugar along with pudding. Many other facts pointed directly to the sugar as the cause. The merchant in question had got a cargo of sugar in five bags or sacks (not barrels) about the beginning cof March, and these were all emptied one after the other into a large barrel for storage, and from this barrel supplies were taken as required into the shop for retailing. Nearly half of the barrel had been disposed of to customers and no ill-health had resulted hitherto when this outbreak suddenly occurred.

On examining the empty sucks, one was found with a stain on each side fully a foot square, which showed plainly athat some fluid material had passed through the sack and its contained sugar at right angles to its long axis Examination of the sugar at the level reached in the barrel showed a quantity more damp and of a darker colour than the rest. As I do not possess a laboratory and could not obtain a supply of sulphuretted hydrogen or other reagents within a reasonable time, I despatched a portion of this sugar to my friend Mr. Falconer King, city analyst, Edinburgh, who kindly telegraphed to me on the Tuesday that the rough tests showed the presence of arsenic, thereby confirming our opinion. Mr. King's report has since then been confirmed by the county and other analysts. On communicating with the wholesale house, the merchant was informed that over 100 bags of the same sugar had been despatched at the same time to various customers, and that there were no other complaints. It was impossible therefore to avoid the conclusion that in transit this particular sack had got part of its contents infiltrated with the poison. So many fluid preparations, such as one particular sheep dip and several weed-killers, contain so much arsenie, and so often leak, that it is not difficult to imagine how the impregnation of the sugar could occur. The patients comprised people of all ages, children suffering least, probably because vomiting being for them such an easy process they at once ejected the poison. In the cases where the poison proved fatal a considerable quantity of the sugar had been partaken of.

Since writing the above I have been informed that the police and the sugar refiners, acting together, have traced the course of the sugar during its transit, and are of opinion that they have discovered the source of the poison-viz., some leaking tins of a liquid weed-killer, with which it is said the sacks were in contact. Samples of this material, and also the stained sack, are in the hands of the public analyst for the county, and the whole matter is engaging the attention of the authorities.

\section{THE GERMAN CONGRESS OF INTERNAL MEDICINE.}

\section{President's Address. - Dr. Naunyn on Gall-stones.}

THE tenth annual meeting of the Congress für innere Medicin took place at Wiesbaden from the 6 th to the 8 th inst. Professor Leyden of Berlin presided, and in his opening address referred briefly to the history of the Congress during the decade of its existence. There had been a notable increase in the number of its associates, although death had robbed them of many eminent colleagues, as von Frerichs, von Langenbeck, and Rïhle. The practice of having subjects chosen for discussion, in which the first two speakers were selected beforehand, had been found of great scientific and practical value. He said that medical science had continued to advance, and although this had led to increasing specialisation, yet "internal medicine" would always continue to be regarded as representative of the whole science; for it dealt with the whole individual, and not merely with special regions of the body. The endeavour towards localisation of disease and the pursuit of local diagnosis and local therapeutics, which characterises the age, ought not to replace the study of general conditions. Curative treatment cannot be limited to local lesions it must be directed towards assisting the whole organism to withstand the inroads of disease. From antiquity these two anims had been kept in view-viz, the subjection of the disease and the treatment of the sick individual; and the task of our time is to follow both lines. The first is being met by the new pharmacology, through various new remedies, and through bacteriology, under the leadership of $R$. Koch; it must be the aim of internal medicine to prevent this tendency becoming too strong. The tenth year of the Congress had been a notable one in the history of medicine. It began with the remarkable epidemic of influenza, then came the Vienna meeting of this Congress, next the International Congress at Berlin, and lastly the discovery of tuberculin. We are still noting the effects of this remedy, and can hardly as yet arrive at a final judgment upon it.

Professor Quincke (Kiel), Demme (Berne), and Naunyn (Strasburg) were the elected vice-presidents, and Drs. Morig (Munich), Mührer (Prague), Reinhold (Freiburg), and Romberg (Leipzig) were appointed secretaries to the Congress.

A discussion upon Diseases due to Gall-stones was then 